\title{
BIBLIOGRAFIA DE Y SOBRE ERNESTO CARDENAL
}

Esta bibliografía se divide en dos partes. La primera presenta las obras escritas por Ernesto Cardenal; la segunda da las obras en torno a él y su producción literaria. En el caso de algunas fuentes proporcionadas por el padre Cardenal, las informaciones están incompletas. Los demás materiales han sido verificados en las bibliotecas de la University of North Carolina at Chapel Hill, la Duke University y Vanderbilt University.

\section{Publicaciones de Ernesto Cardenal}

\section{Obras principales}

\section{Canto nacional}

1. Con un prólogo de Ricardo Morales Avilés. [¿Managua?]: Colección COUN, núm. 6, 1972.

2. Caracas: Ediciones Bárbara, núm. 19, 1973.

3. Buenos Aires: Ediciones Carlos Lohlé, 1973.

En Cuba

1. La Habana: Casa de las Américas, 1970.

2. Buenos Aires: Ediciones Carlos Lohlé, 1972.

\section{Epigramas}

1. Con un prólogo (de Ernesto Mejía Sánchez). México: UNAM, 1961.

2. Buenos Aires: Ediciones Carlos Lohlé, 1972.

\section{El Estrecho Dudoso}

1. Madrid: Ediciones Cultura Hispánica, 1966.

2. Con una introducción de José Coronel Urtecho. San José de Costa Rica: Educa, Colección Séptimo Día, 1971.

3. Buenos Aires: Ediciones Carlos Lohlé, 1972. 
El Evangelio en Solentiname

1. Salamanca: Ediciones Sígueme, Colección Pedal, 1975.

2. Con un prólogo de Antidio Cabal. Caracas: Editorial Signo Contemporáneo, 1976.

Gethsemani, Ky.

1. México: Ediciones Ecuador, 1960.

2. México: Ediciones UNAM, 1961.

3. Medellín: Ediciones La Tertulia [196\%].

Homenaje a los indios americanos

1. León, Nicaragua: Editorial Universitaria, 1969.

2. Con un prólogo de José Miguel Oviedo. Santiago de Chile: Editorial Universitaria de Chile, 1970.

3. Buenos Aires: Ediciones Carlos Lohlé, Cuadernos Latinoamericanos, 1972.

La hora 0

1. Revista Mexicana de Literatura, enero-abril 1957 y abril-junio 1959; también 1960, en un solo número.

2. Montevideo: Aquí Poesía, 1966.

3. En Poesía revolucionaria nicaragüense. México: Ediciones Patria y Libertad, 1968 [tomo de publicación anónima, editado por Ernesto Cardenal y Ernesto Mejía Sánchez].

4. En La hora 0 y otros poemas. Barcelona: El Bardo, 1971 [ya aparece en varias de las otras antologías de Cardenal].

Oración por Marilyn Monroe y otros poemas

1. Medellín: Editorial La Tertulia, 1965.

2. Lima: Instituto Nacional de Cultura, 1972.

Oráculo sobre Managua

1. Managua: Editorial José Martí [1973].

2. Buenos Aires: Editorial Carlos Lohlé, 1973.

\section{Salmos}

1. Con un prólogo de Jorge Montoya Toro. Medellín: Ediciones Universidad de Antioquia (Revista de la Universidad de Antioquia), 1964.

2. Avila, España: Institución Gran Duque de Alba, 1967.

3. Buenos Aires: Ediciones Carlos Lohlé, Cuadernos Latinoamericanos, 1969.

La santidad de la revolución

1. Salamanca: Ediciones Sígueme, Colección Pedal, 1976 [contiene una entrevista, una reimpresión de «Un marxismo con San Juan de la Cruz» y tres poemas: «Condensaciones y visión de San José de Costa Rica), «Epístola a monseñor Casaldáliga» y «Epístola a José Coronel Urtecho»].

\section{Antologías (en orden de su publicación)}

Antología. Santiago de Chile: Editora Santiago, 1967.

Poemas de Ernesto Cardenal. La Habana: Casa de las Américas, Colección La Honda, 1967. 
Antología. San José de Costa Rica: Universidad de Costa Rica, 1971.

Antología, con un prólogo de Pablo Antonio Cuadra. Buenos Aires: Ediciones Carlos Lohlé, Colección Cuadernos Latinoamericanos, 1971.

La hora 0 y otros poemas. Barcelona: E1 Bardo, 1971.

Poemas. Barcelona: Editorial Llibres de Sinera, Colección Ocnos, 1971.

Antología, con una introducción de Mario Benedetti. San José de Costa Rica: Educa, 1972.

Poemas reunidos, 1949-1969. Caracas: Universidad de Carabobo, 1972.

Poemas. Sin lugar: Universidad Simón Bolívar, 1973.

Poesía escogida. Barcelona: Barral, Colección Insulae Poetarum, 1975.

Poemas [sin informaciones; lleva poemas de Ernesto Cardenal y Horacio Peña].

\section{Antologías en traducción}

Anthologie poétique, traducción de A.-M. Métalié y Gérard Bèssière. Paris: Les Éditions du Cerf, Colección Terres de Deu, 1974.

Dalla rivoluzione alla contemplazione politica, traducción de Miara Montonzi y Filippo Gertiloni Silveri. Assissi, Italia: Citadella Editrice, 1974.

Marilyn Monroe and Other Poems, traducción de Robert Pring-Mill. London: Search Press, 1975.

\section{Obras en traducción}

\section{En Cuba}

A Cuba, traducción de Filippo Gertiloni Silveri, con una introducción de Vincenzo d'Agertino. Assissi, Italia: Citadella Editrice, 1975.

In Cuba, traducción de Donald D. Walsh. New York: New Directions, 1974.

In Kuba. Bericht von einer Reise. Hamburg: Siebenstern Tascherburg, 1972.

In Kuba. Wuppertal: Peter Hammer, 1972.

El Evangelio en Solentiname

The Gospel in Solentiname, traducción de Donald D. Walsh. Maryknoll, New York: Orbis Books, 1977.

\section{Homenaje a los indios americanos}

Für die Indianer Amerika. Wuppertal: Peter Hammer, 1973.

Homage to the American Indians, traducción de Monique Altschul y Carlos Altschul. Baltimore: Johns Hopkins Press, 1974.

\section{La hora 0}

«From La hora 0», traducción de Donald D. Walsh, Chicago Review, 27 (otoño 1975), 116-125.

Nulltimer. Wuppertal: Peter Hammer, 1974.

«Zero Hour», traducción de Donald Gardner, El Corno Emplumado, núm. 25 (enero 1968), $1-68$ y $116-130$. 
Oración por Marilyn Monroe y otros poemas

Gebet für Marilyn Monroe und andere Gedichte. Hamburg: Siebenstern Tascherburg, 1972.

Gebet für Marilyn Monroe und andere Gedichte, con una nota de Kurt Marti. Wuppertal: Peter Hammer, 1972.

Marilyn Monroe and Other Poems, traducción de Robert Pring-Mill. London: Search Press, 1975.

Oráculo sobre Managua

«From Oráculo sobre Managua», traducción de Donald D. Walsh, Review (invierno 1973), pp. 49-61.

Orakel über Managua. Wuppertal: Peter Hammer, 1974.

\section{Salmos}

Das Buch von der Liebe: Lateinamerikaanische Psalmen. Hamburgo: Siebenstern Tascherburg, 1972.

Das Buch von der Liebe, traducción de Anneliese Schwarzer de Ruiz. Wuppertal: Peter Hammer, 1971.

En Bok om Kärleken. Wuppertal: Peter Hammer, 1971.

Cri: Psaumes politiques. Paris: Les Éditions du Cerf, 1974.

Grido: Salmi degli oppressi. Assissi, Italia: Citadella Editrice, 1975.

Protest Achter Prikkeldraad: Moderne Zuidamerikaans Psalmen, traducción de J. J. Buske. Amsterdam: W. ter Have, 1968.

Psalms of Struggle and Liberation, traducción de Amile G. McAnany. New York: Herder \& Herder, 1971.

Salms: Clamor d'America. Barcelona: Ediciones Claret, 1973.

Zerschneide deis Stacheldraht, traducción de Stefan Baciu [sin informaciones].

Vida en el amor

Amour, secret du monde. Paris: Éditions du Cerf, 1972.

Canto All'Amore, traducción de Miranda Montossi. Assissi, Italia: Citadella Editrice, 1974.

Love, traducción de D. Livingstone. London Search Press, 1974.

To Live is to Love, traducción de Kurt Reinhardt. Garden City, New York: Doubleday, Image Books, 1974.

To Live is to Love, traducción de Kurt Reinhardt, New York: Herder \& Herder, 1972.

La vida en l'amor, traducción de Joan B. Xuriguera. Barcelona: Ediciones Claret, Colección Els Dares, 1973.

\section{Artículos y antologias por Ernesto Cardenal}

"Ansias y lengua de la nueva poesía nicaragüense».

Tesis, Universidad Nacional Autónoma de México, 1947.

En Orlando Cuadra Downing y Ernesto Cardenal, Nueva poesía nicaragüense. Madrid: Instituto de Cultura Hispánica, 1949 («Ensayo preliminar», pp. 799).

«El arzobispo» (de En Cuba), Taller (Revista de los estudiantes de la UNAM), núm. 8 (enero de 1972), pp. 97-100. 
«La diosa blanca», Cuadernos Hispanoamericanos, núm. 13 (enero-febrero 1950), pp. 175-177 [reseña].

«Don Quijote en Norteamérica», Cuadernos Hispanoamericanos, núm. 13 (enerofebrero 1950), 185-186 [reseña].

"Joaquín Pasos», prólogo a Poemas de un joven. México: Fondo de Cultura Económica, Colección Tezontle, 1962.

Literatura indígena americana, compilado por Ernesto Cardenal y Jorge Montoya Toro. Medellín: Universidad de Antioquía (Revista Universidad de Antioquía), sin fecha.

«El manifiesto de San José», Latinoamérica (Buenos Aires), 1 (diciembre 1972), pp. 67-71 [declaración de los derechos y responsabilidades del escritor e intelectual centroamericano, por Ernesto Cardenal y otros].

Musik, die zum Himmel Steigt; Primitive religiose Poesie, colección e introducción de Ernesto Cardenal. Wuppertal: Juggendiest, 1975.

Poesía cubana de la revolución, colección, prólogo y notas de Ernesto Cardenal. México: Editorial Extemporáneos, 1976.

«La poesía nicaragüense de hoy», La Gaceta (México), 83 (julio 1961).

«La poesía nicaragüense de Pablo Antonio Cuadra», El Pez y la Serpiente, núm. 9 (verano 1968), 121-127.

Poesía nueva de Nicaragua, colección e introducciones de Ernesto Cardenal. Buenos Aires: Ediciones Carlos Lohlé, Cuadernos Latinoamericanos, 1974.

Poesía revolucionaria nicaragïense, colección de Ernesto Cardenal y Ernesto Mejía Sánchez. México: Ediciones Patria y Libertad, 1968.

«Salomón de la Selva: el soldado desconocido».

Rueca (México), núm. 18 (verano 1968), 12-19.

Azul (Managua), enero 1952, pp. 5 y 8.

Alfonso Cortés: treinta poemas, colección e introducción de Ernesto Cardenal. Managua: El Hilo Azul, 1952.

"La voz de un monje en la era nuclear», Papeles de Son Armadans, 36 (enero 1965), 121-126.

\section{Traducciones por Ernesto Cardenal}

Antología de la poesía norteamericana, traducción de Ernesto Cardenal y José Coronel Urtecho. Madrid: Aguilar, 1963.

«Ezra Pound» (selecciones), traducción de Ernesto Cardenal y José Coronel Urtecho, El Corno Emplumado, núm. 24 (1967), 7-25.

«Letanía por los muertos de Vietnam», por Donald Gardner, El Corno Emplumado, núm. 28 (octubre 1968), 98.

«Los neones», por Donald Gardner, El Corno Emplumado, núm. 28 (octubre 1968), p. 98.

Poemas, por Thomas Merton. México: Imprenta Universitaria [¿1961?].

«Poesía nueva norteamericana», traducción de Ernesto Cardenal y José Coronel Urtecho, El Pez y la Serpiente, núm. 3 (marzo 1962), 31-72.

«Salmos», traducido del hebreo por Ernesto Cardenal, Fray Jerónimo y Fray Roberto, El Pez y la Serpiente, núm. 1 (enero 1961), 31-34.

«Varios no», por Ezra Pound, El Pez y la Serpiente, núm. 1 (enero 1961), 129-134. "William Carlos Williams» (selecciones), traducción de Ernesto Cardenal y José Coronel Urtecho, El Corno Emplumado, núm. 25 (enero 1968), 16-31. 


\section{Miscelánea}

"Nota autobiográfica» [bosquejo autobiográfico de Ernesto Cardenal, sin título, en mimeógrafo, sin fecha (anterior a 1970)].

«Diálogo de Caracas» [transcripción de un diálogo con estudiantes de la Universidad Central de Caracas, 16 octubre 1973].

"Coplas a la muerte de Merton', texto anotado", anotaciones de María E. Claro, Revista Chilena de Literatura, núms. 5-6 (1972), 199-218.

«Ernesto Cardenal: poesía», disco fonográfico, colección Voz Viva de América Latina, VVAC-14.

«Ernesto Cardenal: Solentiname», disco fonográfico de poemas, con música de Peter Jannsens, CP DM21.

Cardenal, Ernesto, entrevista con Paul Borgeson, Solentiname, Nicaragua, 1 de enero de 1976.

«Carta a Mr. Griffin», carta fechada «Nuestra Señora de Solentiname, enero 18 [¿1970?]»; 4 pp.

Cartas publicadas en El Corno Emplumado:

A Sergio Mondragón, fechada «Nicaragua, 13 abril 1962», núm. 3 (julio 1962), 133-134.

A Sergio Mondragón, fechada «Antioquia, Colombia, 5 octubre [1962]», número 5 (enero 1963), 46-47.

A Margaret Randall, fechada «Colombia, 20 abril 1963», núm. 7 (julio 1963), 170-171.

Fechada «Colombia, julio 10», núm. 19 (julio 1966).

A El Corno Emplumado, fechada «Nuestra Señora de Solentiname, Nicaragua, febrero 1967», núm. 23 (julio 1967), 153.

A El Corno Emplumado, fechada «Nuestra Señora de Solentiname, mayo 1967», núm. 23 (julio 1967), 154.

«Respuesta a las preguntas de los estudiantes de letras», mimeógrafo, 5 pp. [véase este mismo número de Revista Iberoamericana].

«Sermón de Ernesto Cardenal en una misa de difuntos por el alma del poeta Fernando Gordillo», El Corno Emplumado, núm. 26 (abril 1968), 43-46.

«El sueco» (cuento).

El Pez y la Serpiente, núm. 6 (enero 1965), 78-91.

Antología del cuento centroamericano, pp. 213-225. Ed. por Sergio Ramírez. San José de Costa Rica: Educa, 1973 [esta edición no lleva el epílogo de la otra].

\section{Estudios sobre ERnesto Cardenal}

Aaron, M. Audrey: «Ernesto Cardenal: Contemporary Chilam», en Proceedings of the Pacific Northwest Council of Foreign Languages, parte I, 30 (1974), 193-199.

- «Manrique and Cardenal: no Elegía, sino Alegría», en Proceedings of the Pacific Northwest Council of Foreign Languages, parte I, 36 (1975), 184-191.

Arellano, Jorge Eduardo: «Ernesto Cardenal; de Granada a Gethsemaní (19251957)», en Cuadernos Hispanoamericanos, núms. 289-290 (julio-agosto 1974), 163183. 
- Introducción a Epigramas, de Ernesto Cardenal (Buenos Aires: Ediciones Carlos Lohlé, 1972), pp. 7-9.

BenedetTI, Mario: «Ernesto Cardenal: ¿Evangelio o revolución?». Casa de las Américas, núm. 63 (noviembre-diciembre 1970), 175.

Oposición (Nicaragua, 1970).

Los poetas comunicantes. Montevideo: Biblioteca de la Marcha, 1972.

- «Ernesto Cardenal, poeta de dos mundos».

Antología de Ernesto Cardenal (San José de Costa Rica: Educa, 1972), pp. 9-15.

La Mañana (Montevideo), "Al pie de las letras», 1961.

Letras del continente mestizo, pp. 159-164. (Montevideo: Arca, 1967).

CABal, C. C. Antidio: «La cristianización del cristianismo» (prólogo a El Evangelio en Solentiname, de Ernesto Cardenal). Caracas: Editorial Signo Contemporáneo, 1976.

- «Ernesto Cardenal o el estreno poético-antipoético-antropológico de Occidente», en Imagen (Caracas), núms. 34-35 (15-29 febrero 1972), «segundo cuerpo», pp. 2-3.

CanTón, Wilfredo: «Imágenes de Ernesto Cardenal», en El Centroamericano (León, Nicaragua), núm. 11.653 (7 abril 1968).

Christ, Ronald: "The Poetry of Useful Prophecy: An Interview with Ernesto Cardenal», en Commonweal, 100 (26 abril 1974), 189-191.

Ciccн тто, Vicente: "Homenaje a los indios americanos de Ernesto Cardenal», Ernesto Cardenal: poeta de la liberación latinoamericana, de José Promis Ojeda et al., pp. 135-137 (Buenos Aires: Fernando García Cambeiro, 1975).

Claro, María E.: «Imagen de la vida en las 'Coplas a la muerte de Merton'», en Revista Chilena de Literatura, núms. 5-6 (1972), 219-239.

Cuadra, Pablo Antonio: «Un poeta se va a la Trapa».

La Prensa (Managua), 12 mayo 1957, pp. 1-B y 11-B.

Centroamérica, Revista Cultural del Istmus (México), abril-junio 1957, p. 65.

- «Sobre Ernesto Cardenal».

Papeles de Son Armadans, 63 (año 16), 5-33.

Prólogo a Antología, de Ernesto Cardenal, pp. 9-22 (Buenos Aires: Ediciones Carlos Lohlé, Cuadernos Latinoamericanos, 1971).

Dalton, Roque: «Apuntes de dos encuentros con Ernesto Cardenal», en Ernesto Cardenal/Fidel Castro: cristianismo y revolución, pp. 9.31 (Buenos Aires: Editorial Quetzal, 1974),

Dapaz Strout, Lilia: «Nuevos cantos de vida y esperanza: los Salmos de Ennesto Cardenal y la nueva ética», en Ernesto Cardenal: poeta de la liberación latinoamericana, de José Promis Ojeda et al., pp. 109-131 (Buenos Aires: Fernando García Cambeiro, 1975).

Dorfman, Ariel: «Ernesto Cardenal: todo el poder a Dios-proletariado», en Ensayos quemados en Chile: inocencia y neocolonialismo, pp. 193-223 (Buenos Aires: Ediciones La Flor, 1974).

Elio, Ana Francisca de: «A la búsqueda de un lenguaje para la poesía revolucionaria», en Revista Histórico-Crítica de Literatura Centroamericana, 1 (s. f.), 45-50.

FERnÁndez RetamaR, Roberto: «Antipoesía y poesía conversacional en América Latina», en Panorama de la actual literatura latinoamericana, pp. 251-263 (La Habana: Casa de las Américas, Centro de Estudios Literarios [1969]).

Flores, Fernando Jorge: «Comunismo o reino de Dios: una aproximación a la experiencia religiosa de Ernesto Cardenal», en Ernesto Cardenal: poeta de la libe- 
ración latinoamericana, de José Promis Ojeda et al., pp. 161-196) Buenos Aires: Fernando García Cambeiro, 1975).

FraIRE, Isabel: «Pound and Cardenal», en Review, 18, pp. 36-42.

Freemantle, Anne: «Poetry, Revolution and Theology», en America, 11 enero 1975, pp. 14-15.

Giongis, Jaime de: «Tres poemas de Ernesto Cardenal», en Ernesto Cardenal: poeta de la liberación latinoamericana, de José Promis Ojeda et al., pp. 41-59 (Buenos Aires: Fernando García Cambeiro, 1975).

Goytisolo, José Agustín: «Los poemas de Ernesto Cardenal», en Libre (París), núm. 3 (marzo-abril-mayo 1972), 128.

Guardia, Gloria, y Sandra, Eleta: Con Ernesto Cardenal. Panamá: Ed. Litográfica, 1974.

GutiÉRrez, Pedro Rafael: «Homenaje a Ernesto Cardenal». Managua: Unión de Periodistas de Nicaragua, 1975.

Hoffman Herreros, Johann: Zeitgenossen: Fünfzehn Pen-Portraits. Grünewald, Mainz, por el autor, 1972.

JARA CuAdRA, René: "Charlando con Cardenal», en EAC (Universidad Católica de Chile), núm. 2 (1972).

MARCh DE ORtí, María E.: «Poesía y denuncia de Ernesto Cardenal. Hora 0: estudio temático y estilístico», en Explicación de textos literarios, 5 (1976), 49-58.

Menton, Seymour: Books Abroad, 48 (invierno 1974), 106-107 [reseña de En Cuba].

Merton, Thomas: «Ennesto Cardenal», Universidad de México, núm. 7 (1968), 22.

- Prólogo a Gethsemani, Ky., de Ernesto Cardenal, pp. 5-6 (Medellín: Ediciones La Tertulia [1965]).

- Prólogo a Vida en el amor, de Ernesto Cardenal, pp. 9-22 (Buenos Aires: Ediciones Carlos Lohlé, Cuadernos Latinoamericanos, 1970).

Montes, Hugo, y Rodríguez, Mario: Nicanor Parra y la poesía de lo cotidiano. Santiago de Chile: Editorial del Pacífico, 1970 [pp. 117-137 tratan a Cardenal].

Morales AviLÉs, Ricardo: «Ernesto Cardenal: la misión libertadora de la poesía» (prólogo a Canto nacional, de Ernesto Cardenal, pp. 1-6 [¿Managua?]: Colección COUN, núm. 6, 1972).

Morán, Carlos Roberto: «Los oráculos de Cardenal: carta con opinión», Imagen (Caracas), núm. 94 (15-30 abril 1974), «tercer cuerpo», p. 16 [reseña de Canto nacional y Oráculo sobre Managua].

Murillo, Rosario: «Barro de Dios y del alma india», en La Prensa (Managua), 14 diciembre 1975, pp. 1, 4 y 30.

Notaker, Henry: «Nøte med Ernesto Cardenal», Kirke og Kultur, 79 (Oslo), 140150.

Ossiannilsson, Erik Hjalmar: Die Rätselhafte Gefängnisgeschichte des Schweden (Milgeteilt con Ernesto Cardenal aus Nicaragua), traducción de Helger Castellanos. Wuppertal: Juggendiest, 1970.

Ovalle, Caupolicán: «Entrevista con Ernesto Cardenal», Cal (Caracas), núm. 34 (abril 1964), 10-11.

Oviedo, José Miguel: «Ernesto Cardenal: un místico comprometido».

Imagen (Caracas), núm. 35 (octubre 1968).

Casa de las Américas, 9 (marzo-abril 1969), 29-48.

- Prólogo a Homenaje a los indios americanos, de Ernesto Cardenal. Santiago de Chile: Editorial Universitaria de Chile, 1970. 
- «Un poema necesario».

El Comercio (Lima).

La Prensa (Managua), 30 noviembre 1969, pp. 1 y 3-B.

- «Viejos y nuevos poemas: Ernesto Cardenal».

Vida literaria, 5 (1973), 27-29.

Hoja (San José de Costa Rica), 16.

PRING-MiLL, Robert: "The Christian Revolutionary of Lake Nicaragua», en London Times, Literary Supplement, 12 julio 1974, p. 743.

- Introducción a Marilyn Monroe and Other Poems, pp. 7-32, traducción de Robert Pring-Mill. London Search Press, 1975.

Promis OJEDA, José: «Espíritu y materia: los 'Salmos de Ernesto Cardenal'», en Ernesto Cardenal: poeta de la liberación latinoamericana (Buenos Aires: Fernando García Cambeiro, 1975).

RodRíGUEZ SÁNchEZ, Juan Gregorio: «Materialismo dialéctico-místico en un Salmo de Ernesto Cardenal», en Revista de Literatura Hispanoamericana (Maracaibo), núm. 6 (enero-junio 1974), 51-70.

Ro H wer, Jens: Der Fünfte Psalm: Worte con Ernesto Cardenal, traducción de Stefan Baciu. Zurich: Mosler Verlag, 1972.

Roy, Joaquín: Revista Iberoamericana, 42 (abril-junio 1976), p. 328 [reseña].

Schwarzer De Ruiz, Anneliese de, y Schulz, Hermann: Von der Heiligkeit der Revolution, traducción de Anneliese Schwarzer de Ruiz. Wuppertal: Juggendiest, 1972. (Traducciones en Dalla rivoluzione alla contemplazione politica [Assissi, Italia: Citadella Editrice, 1974], pp. 11-42; El ciervo, agosto-septiembre 1972, y SIC, núm. 352 [febrero 1973], pp. 56-57 y 59-60.)

SosA, Joaquín Marta: "Poemas reunidos (1949-1969) de Ernesto Cardenal», en Imagen (Caracas), núm. 45 (2-9 mayo 1972), «segundo cuerpo», p. 15.

S'TEINSLEger, José: "Ernesto Cardenal: la meta común del cristianismo y el marxismo», en Excelsior (México), «Diorama de la Cultura», 15 febrero 1976, pp. 2-3.

Varela-Ibarra, José L.: «La poesía de Ernesto Cardenal», en Mester (Revista Literaria de los Estudiantes Graduados del Departamento de Español y Portugués, UCLA), 4 (abril 1974), 137-140.

VeIravé, Alfredo: «Ennesto Cardenal: el exteriorismo, poesía del nuevo mundo», en Ernesto Cardenal: poeta de la liberación latinoamericana, de José Promis Ojeda et al., pp. 63-106 (Buenos Aires: Fernando García Cambeiro, 1975).

VILDA DE SAN JuAN, Carmelo: «Ernesto Cardenal: En Cuba», SIC, núm. 352 (febrero 1973), pp. 61-66.

- «La protesta social de un monje poeta: Ernesto Cardenal», SIC, núm. 322 (1970), pp. 89-95.

«Conversación en una tarde chilena», La Opinión (Buenos Aires), 14 octubre 1973. «Los cristianos y la revolución», Quimante, 1972.

«Ernesto Cardenal: el Evangelio en la comuna de Solentiname», SIC, núm. 352 (febrero 1973), 56-57 y 59-60, [traducción de Schwarzer de Ruiz; ha sido atribuida a Manuel Corral].

«¿En Nicaragua los periódicos callan el caso del Perú?», en Semana.

«Ernesto Cardenal, Dino Aranda». Syracuse, New York: Everson Museum of Art, 1973.

«Ernesto Cardenal: ¿profeta de un nuevo cristianismo?», en Avance (San Juan de Puerto Rico), 52-59. 
«La Estafeta Literaria y Oráculo sobre Managua», La Prensa Literaria (Managua), 24 febrero 1974, p. 2.

«Un marxismo con San Juan de la Cruz».

[¿Crisis, agosto de 1974?].

La santidad de la revolución (Salamanca: Ediciones Sígueme, 1976), pp. 55-70.

PaUl W. Borgeson, JR.

University of North Carolina, Chapel Hill. 